\title{
The Effect of Phenoxybenzamine on the Pulmonary Vascular Bed in Surgically Corrected Ventricular Septal Defect Associated with Pulmonary Hypertension
}

Kyoichi Ogawa, M.D., Tetsuo Yamamoto, M.D., Sakae Asada, M.D., Seizo Ifai, M.D., Akira Toriyama, M.D., Kazuhiko Horikoshi, M.D., Masahiro Yamaguchi, M.D., and Ken Kimura, M.D.

\begin{abstract}
SUMMARY
From 1971 to 1977 , a total of 43 cases with ventricular septal defect associated with pulmonary hypertension (VSD $+\mathrm{PH}$ ), ranging from 3 months to 6 years of age, underwent VSD closure using cardiopulmonary bypass with a prophylactic dose of phenoxybenzamine (POB) $1 \mathrm{mg} / \mathrm{Kg}$. Twenty of these cases are included in the present study of the effect of POB on pulmonary hypertension. The ratios of pulmonary to systemic arterial pressures $(\mathrm{Pp} / \mathrm{Ps})$ and vascular resistances (Rp/Rs) were measured before, immediately after and I month after VSD closure. In all cases, the $\mathrm{Pp} / \mathrm{Ps}$ before VSD closure was larger than 0.75 . Both $\mathrm{Pp} / \mathrm{Ps}$ and $\mathrm{Rp} / \mathrm{Rs}$ markedly decreased immediately after VSD closure but rose again 1 month thcreafter. These results suggest the possibility of pulmonary vasodilating effect of $\mathrm{POB}$, which could be potentially useful in reieving the right ventricular load in the early postoperative period. The over all mortality was 3 out of 43 cases including 2 late deaths.
\end{abstract}

\section{Additional Indexing Words :}

Cardiopulmonary bypass Pulmonary vascular resistance Ratio of pulmonary to systemic arterial pressures $(\mathrm{Pp} / \mathrm{Ps}) \quad$ Ratio of pulmonary to systemic vascular resistances $\left(\mathrm{Rp}_{\mathrm{p}} / \mathrm{Rs}\right) \quad$ Correction of ventricular septal defect Low cardiac output syndrome

DENOXYBENZAMINE(POB) is a specific alpha-receptor blocking 1 agent which reduces peripheral vascular resistance, permitting an increase in cardiac output." In cardiac surgery, this agent has been used to improve hypoperfusion states during and after cardiopulmonary bypass. ${ }^{21-6)}$ Recent report has commented upon a selective pulmonary vasodilating effect of $\mathrm{POB}$, which was demonstrated in a preoperative cardiac catheterization. ${ }^{3)}$ This

From the Second Surgical Department, the Department of Anesthesiology, Kobe University School of Medicine and the Department of Surgery, Kobe Children's Hospital.

Address for reprints: Kyoichi Ogawa, M.D., Second Surgical Department, Kobe University School of Medicine, Kusunoki-cho 7, Ikuta-ku, Kobe 650, Japan.

Received for publication July 24, 1978. 
report agrees with our results of $\mathrm{POB}$ during corrective surgery for ventricular septal defect (VSD) associated with pulmonary hypertension (PH), specifically to reduce pulmonary vascular resistance in order to relieve the right ventricular load during the immediate postoperative period.

From 1971 to $1977,43 \mathrm{VSD}+\mathrm{PH}$ cases from 3 months to 6 years of age underwent VSD closure using cardiopulmonary bypass with a prophylactic dose of $\mathrm{POB}(1 \mathrm{mg} / \mathrm{Kg})$. In all cases, the ratio of pulmonary to systemic arterial pressures $\left(\mathrm{Pp}_{\mathrm{p}} / \mathrm{P}_{\mathrm{s}}\right)$ was larger than 0.75 , preoperatively. In the most recent 20 consecutive cases, pulmonary and systemic arterial pressures were recorded before, immediately after and 1 month after operation. The $\mathrm{Pp} / \mathrm{Ps}$ and the ratio of pulmonary to systemic arterial resistances $(R p / R s)$ were calculated for the study of the effect of $\mathrm{POB}$ on the pulmonary vascular resistance. This paper will present and discuss the effect of $\mathrm{POB}$ on pulmonary vascular resistance in VSD+PH.

\section{Materials and Methods}

Of the 43 cases of VSD+PH undergoing corrective surgery with POB, 20 cases were subjected to the present study. For bypass procedure, a Temptrol bubble oxygenator was primed with lactate Ringer solution and heparinized blood providing 30\% hemodilution of total circulating blood volume. An aortic cannual was connected to the arterial line of the oxygenator with a pump-output of 2.4 to $3.2 \mathrm{~L} / \mathrm{M}^{2} / \mathrm{min}$ under normothermia or mild hypothermia $\left(28-36^{\circ} \mathrm{C}\right)$. After aortic cannulation, an infusion of POB $(1 \mathrm{mg} / \mathrm{Kg}$, diluted in 30 to $50 \mathrm{ml}$ of $5 \%$ dextrose in water) was started 15 to 30 min prior to the beginning of bypass. During administration of $\mathrm{POB}$, blood was transfused to correct the relative hypovolemia resulting from $\mathrm{POB}$ administration, which was monitored by blood pressure and central venous pressure. Cardiopulmonary bypass was started at the completion of $\mathrm{POB}$ administration. At the end of the intracardiac procedures, systemic and pulmonary arterial pressures were simultaneously recorded, while the patients inspired 50\% oxygen. One month after operation, all cases underwent cardiac catheterization under general anesthesia with inspiration of $50 \%$ oxygen, and the $\mathrm{Pp} / \mathrm{Ps}_{\mathrm{s}}$ and $\mathrm{Rp} / \mathrm{Rs}$ were calculated.

\section{RESUlts}

The $\mathrm{Pp} / \mathrm{Ps}$ before operation ranged from 0.75 to 1.16 with a mean of 0.94. At the end of intracardiac procedures, the $\mathrm{Pp} / \mathrm{Ps}$ became 0.20 to 0.66 with a mean of 0.41 . One month after operation, the $\mathrm{Pp} / \mathrm{Ps}$ rose to the range of 0.25 to 1.02 with a mean of 0.56 (Fig. 1).

The preoperative $R_{p} / R_{s}$ ranged from 0.08 to 0.87 with a mean of 0.48 . At the end of correction of VSD, the value ranged from 0.16 to 0.50 with a 


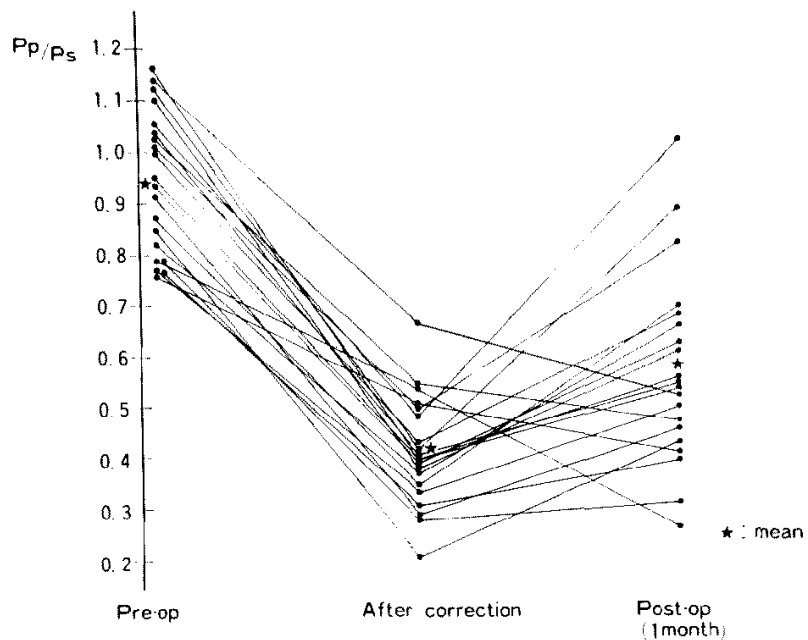

Fig. 1. The ratio of pulmonary to systemic arterial pressures before, immediately after correction of VSD and I month after operation.

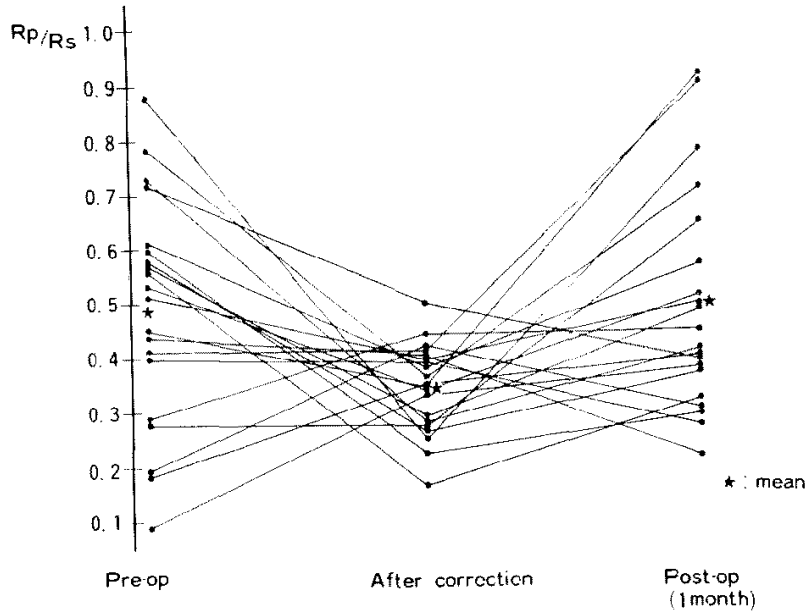

Fig. 2. The ratio of pulmonary to systemic arterial resistances before, immediately after correction of VSD and 1 month after operation.

mean of 0.34 . One month after operation, the $\mathrm{Rp} / \mathrm{Rs}$ ranged from 0.21 to 0.91 with a mean of 0.49 (Fig. 2).

In 4 of the 20 cases, the $\mathrm{Rp} / \mathrm{Rs}$ measured 1 month after operation was more than 0.70. However, the $\mathrm{Rp} / \mathrm{Rs}$ at the end of intracardiac procedures was below 0.42 in all 4 cases. Of a total of 43 cases undergoing correction of VSD with $\mathrm{POB}, 1$ operative death was encountered. The patient died of ventricular arrhythmia on the 10th postoperative day, the cause of which was unknown. The 2 other cases died of respiratory failure on the 110 th and 
162nd postoperative days respectively. No mortality occurred in the most recent 20 cases which were subjected to this study.

\section{Discussion}

After correction of VSD, remaining high pulmonary vascular resistance is one of the most serious problems affecting operative results as pointed out by Cartmill et al, ${ }^{7}$ and others. ${ }^{81,9)}$ Persistent high pulmonary vascular resistance after closure of VSD increases right ventricular load during the immediate postoperative period, resulting in low cardiac output state and in increased mortality.

The acute fall of $\mathrm{Pp} / \mathrm{Ps}$ and $\mathrm{Rp} / \mathrm{Rs}$ seen immediately after correction of VSD is assumed to be the results of both anatomical closure VSD and the effect of POB to dilate the pulmonary vascular bed. Because the rise of $\mathrm{Pp} / \mathrm{Ps}_{\mathrm{s}}$ and $\mathrm{Rp} / \mathrm{Rs} 1$ month after the operation was seen in a total of 16 cases among the 20, POB is assumed to be significantly effective in reducing pulmonary vascular resistance.

Other factors reducing pulmonary vascular resistance, such as tolazoline hydrochloride (priscoline), ${ }^{10)}$ hexamethonium bromide $\left(\mathrm{C}_{6}\right),{ }^{11)}$ acetylcholine, ${ }^{12)}$ oxygen, ${ }^{13), 14)}$ and artificial ventilation ${ }^{15)}$ etc have also been reported.

Because artificial ventilation using high concentration of oxygen is routinely used during the immediate postoperative period, the effect of these factors is not negligible. Therefore, we measured pulmonary and systemic pressures under general anesthesia with $50 \%$ oxygen inspiration preoperatively, during operation and postoperatively, to eliminate the effect of above mentioned factors.

As for the effect of $\mathrm{POB}$ on pulmonary vascular resistance, Ohta et al, ${ }^{3)}$ reported that a decrease of $\mathrm{Pp} / \mathrm{Ps}$ from 0.80 to 0.71 and $\mathrm{Rp} / \mathrm{Rs}$ from 0.59 to 0.40 were observed after the administration of $\mathrm{POB}$ in cases of patent ductus arteriosus associated with pulmonary hypertension $(\mathrm{PDA}+\mathrm{PH})$ and VSD+ $\mathrm{PH}$ during preoperative cardiac catheterization. To our knowledge, no report has ever been presented about the effect of POB on pulmonary vascular resistance concerning the corrective surgery of VSD $+\mathrm{PH}$.

Many authors including us have already reported that POB markedly reduces systemic vascular resistance in clinical subjects. ${ }^{1-6)}$ In this series of 43 surgical cases of VSD $+\mathrm{PH}$ including twelve infants under 12 months of age, only 1 operative death was seen in a 3-month-old baby who developed ventricular arrhythmia on the 10th postoperative day. Low cardiac output syndrome was noticed in only 2 cases including the dead case.

According to the results, it may be concluded that the effect of POB 
in reducing both systemic and pulmonary vascular resistances seemed to prevent low cardiac output syndrome by decreasing cardiac load and resulted in satisfactory outcomes in this series.

\section{REFERENCES}

1. Skillman JJ, Elitringham WK, Zollinger RM, Lauler DP, Moore FD: Phenoxybenzamine induced vasodilatation. A stimulus to increased plasma volume with reduced CVP and aldosterone hypersecretion in man. Surgery 64: 368, 1968

2. Lillehei RC, Lillehei CW, Grismer JT, Levy MJ: Plasma catecholamines in open-heart surgery; the prevention of their pernicious effects by pretreatment with Debenzyline. Surg Forum 14: 269, 1963

3. Ohta Y: Phenoxybenzamine in cardiac sugery. Resp \& Circ 22: 495, 1974 (in Japanese)

4. Ogawa K, Kimura K, Toriyama A, Horikoshi K, Kawai Y, Horiguchi S, Kaneda H, Asada S, Kawasaki T, Taninaka K, Yamamoto T, Miyata A, Otani S, Iwai S: Phenoxybenzamine in open heart surgery in infants and children. Heart 5: 1561, 1973 (in Japanese)

5. Sakauchi G, Anzai T, Oki T, Iino A, Matsumoto H, Ida J, Asaumi H, Nomoto C: The application of phenoxybenzamine in open heart surgery using cardiopulmonary bypass. $J$ Cadiovase Surg 17: 314, 1976

6. Kurahashi $\mathrm{H}$ : Effects of phenoxybenzamine (POB) on the heart and circulatory system and its application to open heart surgery. JJATS 21: 849, 1973 (in Japanese)

7. Cartmill TB, DuShane MD, McGoon DC, Kirklin MD: Result of repair of ventricular septal defect. J Thorac Cardiovasc Surg 52: 486, 1966

8. Wertheimer M, Moller JH, Castaneda AR: Pulmonary hypertension and congenital heard disease. Ann Thorac Surg 16: 416, 1973

9. Shohtsu A, Takeuchi S, Sohma Y, Inoue T: Surgical indication and results in ventricular septal defect associated with severe pulmonary hypertension. J Cardiovasc Surg 17: 13, 1976

10. Rudolph AM, Paul MH, Sommer LS, Nadas AS: Effects of tolazoline hydrochroride (Priscoline) on circulatory dynamics of patients with pulmonary hypertension. Am Heart J 55: 424,1958

11. Ito $\mathrm{K}$ : Studies on pulmonary hypertension in cardiac surgery. Jap. Circulat J 23: 830, 1959 (in Japanese)

12. Shepherd JT, Semler HJ, Helmholz HF, Wood EH: Effects of infusion of acetylcholine on pulmonary vascular resistance in patients with pulmonary hypertension and congenital heart disease. Circulation 11: 381, 1959

13. Swan HJC, Burchell HB, Wood EH: Effect of oxygen on pulmonary vascular resistance in patients with pulmonary hypertension associated with atrial septal defect Circulation 20: 66,1959

14. Takahara I: Study of postoperative changes of the pulmonary hemodynamics by 100 percent oxygen inhalation in the ventricular septal defects associated with pulmonary hypertension. JJATS 22: 891, 1974 (in Japanesc)

15. Fujioka Y, Yamamoto H, Motomura R, Ouchi Y, Hara H, Sagara Y, Hatajima H, Yokokura $\mathrm{Y}$, Toyomasu H, Kosuga K, Takagi H, Oishi K, Koga M. Pulmonary hemodynamics in ventricular septal defect with pulmonary hypertension after surgical correction. Jap $\mathrm{J}$ Thorac Surg 29: 332, 1976 (in Japanese) 